\title{
On the Priority of the Study on the Reaction of Polychloronorbornenes with Pyridine
}

\author{
S. A. Mamedov \\ Baku International Environmental Center \\ e-mail:m.sabrikenan@rambler.ru
}

Received January 28, 2013

DOI: $10.1134 / \mathrm{S} 1070428013060304$

We previously [1] discovered the reaction of polychloronorbornenes with pyridine in DMF, which led to the formation of the corresponding 1,2,3,4-tetrachlorocyclohexa-1,3-dienes as a result of cleavage of the dichloromethylene bridge.
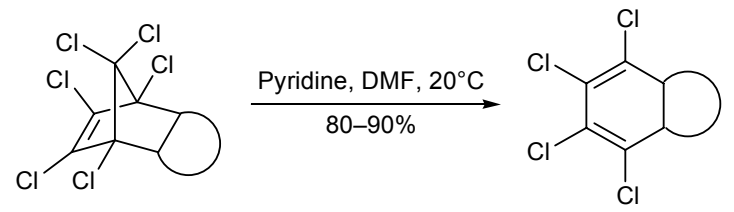

M.S. Salakhov and co-workers, without citing our results, published later analogous results as novel $[2,3]$. The scientific novelty of Salakhov's studies $[2,3]$, consisting of revealing cleavage of the dichloro- methylene bridge in polychlorinated norbornenes and conditions of the reaction and isolation of the products, was literally identical to the data reported by us in [1].

Taking into account the above stated, the authors of [1] consider Salakhov's publications $[2,3]$ to be plagiarism which violates our author's rights.

\section{REFERENCES}

1. Mamedov, S.A., Kuliev, A.B., Akhmedov, Sh.T., and Zefirov, N.S., Zh. Org. Khim., 1991, vol. 27, p. 2228.

2. Salakhov, M.S., Umaeva, V.S., and Alikhanova, A.I., Russ. J. Org. Chem., 2008, vol. 44, p. 1438.

3. Salakhov, M.S., Umaeva, V.S., and Alikhanova, A.I., Russ. J. Org. Chem., 2008, vol. 44, p. 1611. 